\title{
HIV Seroprevalence among the Patients or Clients Obtaining Blood Sample at BSMMU Virology Laboratory
}

\author{
Nahida Sultana, Mahbuba Sharmin, Tangia Muquith, and Umme Shahera
}

\section{ABSTRACT}

Departments of Virology (DVs), BSMMU receive patients from every background, socioeconomic group and health status. Hence, DVs can play a critical role in offering human immunodeficiency virus (HIV) testing and help in the national strategy of early HIV detection. The present study was conducted on 1208 patients attending DVs after taking Institutional Review Board approval. They were screened for HIV antibodies by three rapid/simple assay tests having different principles/antigens as per the WHO guidelines. Forty four $(\mathbf{1 3 . 6 \%})$ of the 1208 patients were HIV reactive and $1164(96.4 \%)$ were negative respectively. Distribution of patients on the basis of gender where $894(74.1 \%)$ were male and $313(25.9 \%)$ were female out of 1208 patients or clients. Distribution of study subject on the basis of exposure history where $378(38.8 \%$ ) patients or clients had history of exposure and $830(68.7 \%)$ patients or clients did not. Distribution of the patients on the basis of purpose of screening where patients were in three groups (Screening before operation, Positive exposure history and To exclude HIV infection during failure of drug Rx) where 776(64.2\%) patients were done anti-HIV test due to screening purpose before operation, 378(31.1\%) patients were done this test due to Positive exposure history exposure history and $54(4.5 \%)$ patients done this due to exclude HIV infection during failure of drug treatment. Prevalence of HIV infection was more among 21-40yrs age group than other age group(18mon-20yrs,4160yrs\& $>60 y r s$ ) which is not significant . Data shows there was significant association of anti-HIV positivity with exposure history of the patients or clients. Prevalence of HIV infection was more among patients or clients who had history of exposure. Prevalence of HIV was more among the patients who were done screening test due to failure of drugs than other two purposes. Bangladesh is still considered as a low HIV/AIDS prevalent country. However, it is at a critical moment in the course of its AIDS epidemic. It is estimated that there are 13,000 HIV-positive people in the country and that HIV prevalence in the adult population is less than $0.01 \%$. However, the country's vulnerability is very high. National HIV surveillance indicates that the rate of HIV infection among street-based sex workers in central Bangladesh is high compared with sex workers in other parts of South Asia. HIV among injecting drug users is already $10.5 \%$. The presence of covert multi-partner sexual activity and denial, the low level of knowledge and low condom use, unsafe professional blood donations, lack of a desirable environment and violation of Human Rights, all contribute to the spread of HIV in Bangladesh. Thus, the study emphasizes the need for expansion of routine voluntary HIV counseling and testing to all the patients who come to the DV and practicing universal work precautions by health care workers.

Keywords: bangladesh, department of virology, human immunodeficiency virus, rapid test, universal work precautions
Published Online: Ferbruary 13, 2021

ISSN: 2736-5476

DOI : 10.24018/ejclinicmed.2021.2.1.15

Dr. Nahida Sultana*

Departent Of Virology, BSMMU,

Dhaka, Bangladesh

(e-mail: nahida.sultanabd@gmail.com)

Dr. Mahbuba Sharmin

Departent Of Heamatology, BSMMU, Dhaka,Bangladesh

(e-mail: dr.sharmin1012@gmail.com)

Dr. Tangia Muquith

Hematology and Stem Cell Transplant Department, BSMMU, Dhaka, Bangladesh

(e-mail: tangia32ssmc@gmail.com )

Dr. Umme Shahera

Departent Of Virology, BSMMU,

Dhaka,Bangladesh

(e-mail: sammamjuhaer yahoo.com )

*Corresponding Author

\section{INTRODUCTION}

The department Virology (DV) is an ideal place for public health interventions and provides ready access to the health care system, offering a great opportunity for human immunodeficiency virus (HIV) testing and counselling. DVs receive patients from every background, socioeconomic group and health status. Hence, DVs are a key component of the health care safety net. Patients not linked with health services are particularly likely to seek care in an DV when medical concern arises.[1] The country faces a concentrated epidemic, and it's very low HIV-prevalence rate is partly due to prevention efforts, focusing on men who have sex with men, female Sex workers and intravenous drug users. [2] However, it has been seen that HIV infection is diagnosed most of the times with one or the other opportunistic infection (OI), particularly in developing countries. At the time of diagnosis, most of the patients have advanced disease and are at a higher risk of OIs and death. 
Emergencies in HIV-infected patients can occur at any stage of the disease. DVs can play a critical role in offering HIV testing and help in the national strategy of early HIV detection. Early detection will allow the infected individuals to take full advantage of Anti retroviral therapy (ARTs) and preventive medicines for opportunistic infections.[3] Emergency medical personnel must assiduously guard against accidental needle stick injury by practicing universal work precautions (UWPs) strictly as they present the greatest risk for health care work-related HIV infection.[4]

\section{METHODS}

The present study was conducted on 1208 patients from Department of Virology, BSMMU for HIV antibodies after taking approval from the Institutional Review Board. Detailed history was taken. Pre-test counseling of the patients was performed and their informed consent was taken before blood sample collection. HIV antibodies were detected by ELISA and various rapid/simple assay tests using different antigens and principles as per the WHO guidelines provided at Department of Virology BSMMU.

Patient's serum was first tested using Enzyme Linked Immuno Sorbent Assay (ELISA) was done to detect specific antibody to HIV using 3rd generation enzyme immune assay, Biotest; Germany. Capillus were done on HIV positive serum to recheck the results of ELISA test. The sensitivity and specificity of the biotest Anti-HIV TETRA ELAISA was $100 \%$ and $99.83 \%$.In case of HIV rapid tests (capillus) that can be obtained through the WHO bulk procurement scheme they have been evaluated and have met pre set criteria. The levels of sensitivity and specificity of Capillus is greater than or equal to $99 \%$.Incase of test in Parallel sample were positive in both test that sera is positive for HIV. It should be remembered that no test $100 \%$ sensitive and $100 \%$ specific. WHO recommends serial testing in most setting because more economic, a second test being required only when the initial test is positive. The results were tabulated and analyzed using the chi-square test and $P$-value $<0.05$ was taken as statistically significant. Post-test counseling was carried out for those who were found to be HIV reactive and were referred to the ART Center, BSMMU, for treatment.

\section{RESULTS}

A total of 1208 study subjects were tested for antibody to HIV by ELISA and capillus method .The seroprevalence of anti-HIV in Patients or clients is shown in figure 1. Out of 1208 subjects, 44(13.6\%) were positive and 1164(96.4\%) were negative respectively.

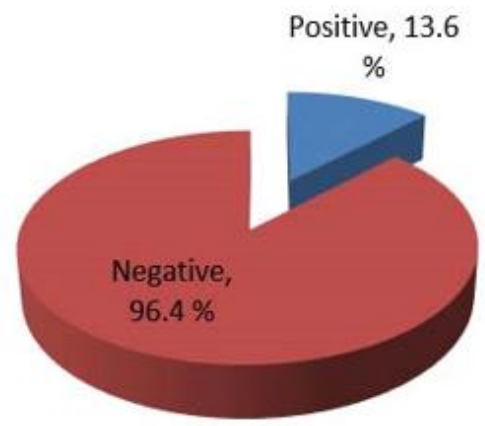

- Positive

Negative

Fig. 1. Distribution of study subjects by anti-HIV antibody test
Table 1 shows the mean age of patients or clients were 41.51 years ranging from 18 month to more than $60 \mathrm{yrs}$. Highest percentage of patients were in 21-40 years of age group $(72.5 \%)$ followed by 18 month to 20 years age group $(13.6 \%)$ and lowest percentage were present in more than 60years age group $(0.8 \%)$. Distribution of patients on the basis of gender where $894(74.1 \%)$ were male and 314 (25.9\%) were female out of 1208 patients or clients. The table also shows distribution of study subject on the basis of exposure history where $378(31.1 \%)$ patients or clients had history of exposure and $830(68.7 \%)$ patients or clients did not. Table shows the distribution of the patients on the basis of purpose of screening where patients were in three groups (Screening before operation, Positive exposure history and To exclude HIV infection during failure of drug $\mathrm{Rx}$ ) where $776(64.2 \%)$ patients were done anti-HIV test due to screening purpose before operation, 378(31.1\%) patients were done this test due to Positive exposure history exposure history and 54(4.5\%) patients done this due to exclude HIV infection during failure of drug treatment.

TABLE I: DEMOGRAPHIC PROFILE OF THE STUDY POPULATION

\begin{tabular}{|c|c|c|}
\hline \multicolumn{3}{|c|}{$(\mathrm{N}=1208)$} \\
\hline & Frequency & Percentage \\
\hline \multicolumn{3}{|l|}{ Age } \\
\hline 18 month-20yrs & 164 & 13.6 \\
\hline $21-40 y r s$ & 876 & 72.5 \\
\hline $41-60 \mathrm{yrs}$ & 158 & 13.1 \\
\hline$>60 \mathrm{yrs}$ & 10 & 0.8 \\
\hline Total & 1208 & 100 \\
\hline \multicolumn{3}{|c|}{ *Mean Age $=41.51 ;$ range $=18 \mathrm{mon}->60 \mathrm{yrs}$} \\
\hline \multicolumn{3}{|l|}{ Gender } \\
\hline Male & 894 & 74.1 \\
\hline Female & 314 & 25.9 \\
\hline \multicolumn{3}{|l|}{ Exposure history } \\
\hline Yes & 378 & 31.1 \\
\hline No & 830 & 68.7 \\
\hline \multicolumn{3}{|l|}{ Purpose of screening test } \\
\hline Screening before operation & 776 & 64.2 \\
\hline Positive exposure history & 378 & 31.1 \\
\hline $\begin{array}{l}\text { To exclude HIV infection during } \\
\text { failure of drug Rx }\end{array}$ & 54 & 4.5 \\
\hline
\end{tabular}

Data shows there was no significant association between age of study subjects and HIV infection in figure 2 .Prevalence of HIV infection was more among 21-40 yrs age group than other age group(18mon-20yrs, 41-60yrs \& $>60 \mathrm{yrs}$ ) which is not significant.

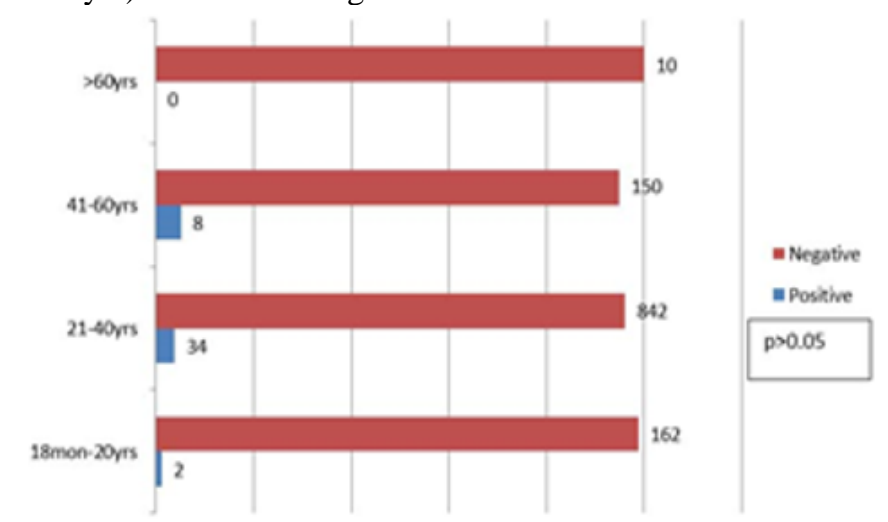

Fig. 2. Relationship between age of the patients or clients and anti-HIV antibody test 
Data in figure 3 shows there was significant association of anti-HIV positivity with exposure history of the patients or clients .Prevalence of HIV infection was more among patients or clients who had history of exposure.

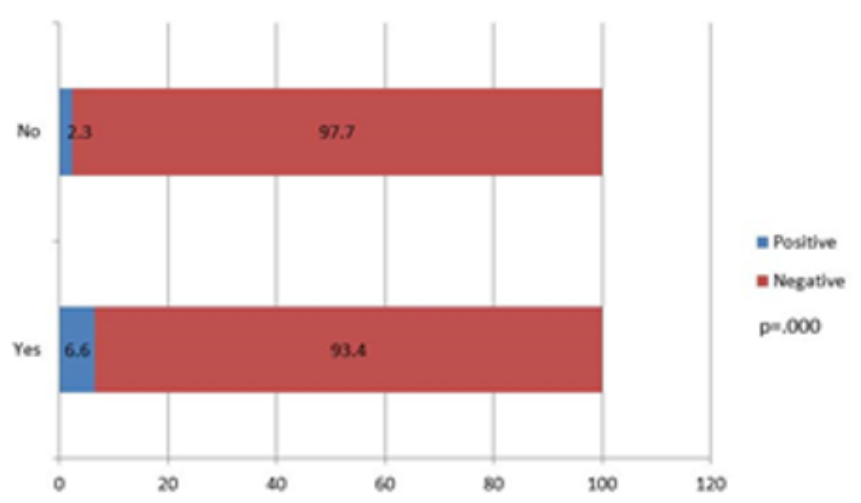

Fig. 3. Association of anti-HIV positivity with exposure history of the patients of clients

Data shows there was significant association between HIV positive patients or clients and purpose to exclude HIV during failure of treatment. Prevalence of HIV was more among the patients who were done screening test due to failure of drugs than other two purpose.

TABLE II: RELATIONSHIP BETWEEN AGE OF THE PATIENTS OR CLIENTS AND ANTI-HIV ANTIBODY TEST

\begin{tabular}{|l|l|l|l|l|}
\hline \multirow{2}{*}{$\begin{array}{l}\text { Purpose } \\
\text { screening }\end{array}$} & \multicolumn{2}{|l|}{ Anti-HIV antibody test } & Total & \multirow{2}{*}{$\begin{array}{l}\text { P } \\
\text { value }\end{array}$} \\
\cline { 2 - 4 } & Positive & Negative & & \\
\hline $\begin{array}{l}\text { Screening before } \\
\text { operation }\end{array}$ & $4(0.5 \%)$ & $772(99.5 \%)$ & 776 & \\
\hline $\begin{array}{l}\text { Positive exposure } \\
\text { history }\end{array}$ & $25(6.6 \%)$ & $353(93.4 \%)$ & 378 & 0.000 \\
\hline $\begin{array}{l}\text { To exclude HIV } \\
\text { during failure of } \\
\text { Rx }\end{array}$ & $15(27.8 \%)$ & $39(72.2 \%)$ & 54 & \\
\hline Total & 44 & 1164 & 1208 & \\
\hline
\end{tabular}

\section{DISCUSSION}

HIV infection is becoming a global public health problem. The pandemic is not homogeneous within regions, with some countries more afflicted than others. ${ }^{[15]}$ Even at the country level, there are wide variations in infection levels between different areas. The number of people infected with HIV continues to rise in most parts of the world, despite the implementation of prevention strategies, Sub-Saharan Africa being by far the worst-affected region, with an estimated 36.9 million at the end of 2017, 1.8 million individuals worldwide became newly infected with HIV in $2017^{[5]}$. South \& South East Asia has an estimated $12 \%$ of the global total. ${ }^{[6,16,17,18]}$

This study was a cross sectional study carried out with the aim to determine the HIV seroprevalence among patients/clients obtaining blood sample at BSMMU virology laboratory. Study shows that the mean age of patients or clients were 41.51 years ranging from 18 month to more than 60 yrs. Highest percentage of patients were in 21-40 years of age group $(72.5 \%)$ followed by 18 month to 20 years age group $(13.6 \%)$ and lowest percentage were present in more than 60 years age group $(0.8 \%)$. Prevalence of HIV infection was more among 21-40yrs age group than other age group (18mon-20yrs, 41-60yrs \& >60yrs) which is not significant. Highest percent of all new HIV infections occur among young people between $15-24$ years old ${ }^{[7,8]}$.Sexually transmitted infections have significant implications for the vulnerability of young people to HIV. High rates of STIs among young people reveal the high levels of unprotected sex, which puts them at risk for contracting HIV. STIs are most frequent in young people aged $15-24$, and 50 per cent of all HIV infections are among young people, most of whom contract HIV before they are 20 years old ${ }^{[9]}$.

The seroprevalence of anti-HIV in Patients or clients is shown in figure 1. Out of 1208 subjects, 44(13.6\%) were positive and $1164(96.4 \%)$ were negative respectively. On a global scale, the HIV epidemic has stabilized, although with unacceptably high levels of new HIV infections and AIDS deaths. In December 2018, about 1,700 people have been newly affected by the virus. Around 4,700 people are diagnosed with the virus. However, only 2,470 AIDS affected people in the country are receiving antiretroviral therapy (ART), according to the report. However, UNAIDS reported there were some 11,000 people living with HIV out of a total population of 150 million ${ }^{[3,10]}$. According to UNIAIDS adult prevalence rate was $<.01 \%$ at end of 2005.Gender inequity, condoned both culturally and socially in parts of Asia, heightens the vulnerability of women and girls at many levels. Unequal access to education means that girls often have less access to important information to protect their health and well being. Distribution of patients on the basis of gender where $894(74.1 \%)$ were male and $313(25.9 \%)$ were female out of 1207 patients or clients. Cultural mores are more likely to allow men to have multiple sex partners and patronize commercial sex establishments while wives are expected to remain faithful [11]. New trends in the epidemic are revealing that faithful, monogamous wives are now becoming infected when their husbands bring home the virus ${ }^{[12]}$.

Unprotected sexual intercourse, whether men with men or women with men, is the most common way of transmitting HIV.Between 85-90 percent of new infections are transmitted through sexual intercourse ${ }^{[13]}$. Distribution of study subject on the basis of exposure history where $378(38.8 \%)$ patients or clients had history of exposure and $830(68.7 \%)$ patients or clients did not. Data shows there was significant association of anti-HIV positivity with exposure history of the patients or clients. Prevalence of HIV infection was more among patients or clients who had history of exposure. In the context of HIV epidemics, the notion of "bridging" refers to the group of people who connect high risk and low risk populations. Men who sex with commercial Sex workers and also with monogamous wives are an example of a bridging population. The larger the bridging group, the greater the risk of transmission into the general population. HIV spreads extensively in populations where the level of sex partner exchange is sufficiently high. ${ }^{[14]}$

Distribution of the patients on the basis of purpose of screening where patients were in three groups (Screening before operation, Positive exposure history and To exclude HIV infection during failure of drug Rx) where 776(64.2\%) patients were done anti-HIV test due to screening purpose before operation, $378(31.1 \%)$ patients were done this test due to Positive exposure history exposure history and 54(4.5\%) patients done this due to exclude HIV infection 
during failure of drug treatment. Data shows there was significant association between HIV positive patients or clients and purpose to exclude HIV during failure of treatment .Prevalence of HIV was more among the patients who were done screening test due to failure of drugs than other two purposes. For instance, a study by Julien et al. posited that Positive HIV results were found in $8.3 \%$ of case during preoperative testing in a low resource country. ${ }^{[19,20]}$. No other study found to compare this study finding.

However, despite the availability of this widening array of effective HIV prevention tools and methods and a massive scale-up of HIV treatment in recent years, new infections among adults globally have not decreased sufficiently.

\section{LIMITATION}

Like other studies, this study has some limitations. First, being a cross sectional study, we only observe cannot determine variable of HIV. Secondly, the choice of only one tertiary hospital for the study.

\section{CONCLUSION}

HIV testing should be integrated with screening for other infections such as viral hepatitis, sexually transmitted diseases and tuberculosis. Because populations disproportionately affected by HIV are also disproportionately affected by these infections, integrating these services can significantly improve health care services. Thus, the study emphasizes the importance of offering rapid HIV testing to all patients who present in the VD with or without symptoms. Routine testing might increase the linkage of HIV-positive persons to health and prevention services earlier in the course of infection, which might result in improved long-term prognosis and reduced HIV transmission.

\section{REFERENCES}

[1] A novel emergency department based prevention intervention program for people living with HIV: evaluation of early experiences. Available from: http://www.biomedicentral.com/1472-6963/164[last cited on 2008 Jun 6]

[2] "Health Profile: Bangladesh". United States Agency for International Development (March 2008). Accessed August 25, 2008.

[3] Teja VD, Sudha T, Lakshmi V. Emergency department based HIV screening: An opportunity for early diagnosis in high prevalent areas. Indian J Med Microbiol. 2008;26:167-71.

[4] Kizer KW. HIV disease and emergency medicine. Western Journal of Medicine. 1989 Jul;151(1):65.

[5] Global StatisticsI HIV.govhttps://www.hiv.gov/hivbasics/overview/data-and-trends/global-statistics

[6] Rodrigo C, Rajapakse S. Current status of HIV/AIDS in South Asia. Journal of global infectious diseases. $2009 \mathrm{Jul} ; 1(2): 93$.

[7] Ezenekwe E, Uduak NE, Nnamani C. 1279. Prevalence of HIV Among the Youth Aged 15-24 in Nigeria: A Need to Increase Access for Young Adolescents to HIV Counseling and Testing. InOpen Forum Infectious Diseases 2018 Nov (Vol. 5, No. Suppl 1, p. S390). Oxford University Press.

[8] Ssebunya RN, Wanyenze RK, Namale L, Lukolyo H, Kisitu GP, Nahirya-Ntege P, Kekitiinwa A. Prevalence and correlates of HIV testing among adolescents 10-19 years in a post-conflict pastoralist community of Karamoja region, Uganda. BMC public health. 2018 Dec 1;18(1):612.

[9] Comins CA, Rucinski KB, Baral S, Abebe SA, Mulu A, Schwartz SR. Vulnerability profiles and prevalence of HIV and other sexually transmitted infections among adolescent girls and young women in Ethiopia: A latent class analysis. PloS one. 2020 May 14;15(5):e0232598.

[10] Azim T, Khan SI, Haseen F, Huq NL, Henning L, Pervez MM, Chowdhury ME, Sarafian I. HIV and AIDS in Bangladesh. Journal of health, population, and nutrition. 2008 Sep;26(3):311.

[11] UNFPA, 1997 State of the Worlds Population Report.Tan, Michael and Tim Brown, 1994, "Social Policy, human rights, and HIV/AIDS in Asia and the Pacifc." AIDS 8:s207-s213, quoted in Ahlburg, Dennis and Eric Jensen, 1997, "The Economics of the Commercial Sex Industry and Its Implications for HIV/AIDS Prevention Policies,"

[12] Tan, Michael and Tim Brown, 1994, "Social Policy, human rights, and HIV/AIDS in Asia and the Pacifc." AIDS 8:s207-s213, quoted in Ahlburg, Dennis and Eric Jensen, 1997, "The Economics of the Commercial Sex Industry and Its Implications for HIV/AIDS Prevention Policies,"

[13] WHO/SEARO, 1995, "Progress Towards Prevention and Control of AIDS in South-East Asia," Report of the 11th Meeting of the National AIDS Programme Managers, p.1.

[14] Chin, James, 1995, "Scenarios for the AIDS epidemic in Asia." AsiaPacific Population Research Reports. No.2. Hawaii: East West Center Program on Population, p.12.

[15] WHO. Why the HIV epidemic is not over. Available via https://www.who.int/hiv-aids/latest-news-andevents/why-the-hivepidemic-is-not-over Accessed 10 August 2019).

[16] WHO. Global Health Observatory Data. Summary of the global HIV epidemic (2018). Available via https://www.who.int/gho/hiv/en/ Accessed 10 August 2019).

[17] Joint United Nations Programme on HIV/AIDS (UNAIDS). AIDS by the numbers. Jc2571/1/E, pp 1-11, 2015. Available via https://www.unaids.org/ sites/default/files/media_asset/AIDS-by-thenumbers-2016_en.pdf; doi:JC2571/1/E

[18] Kharsany ABM, Karim QA. HIV Infection and AIDS in SubSaharan Africa: current status, challenges and opportunities. Open AIDS J. 2016; 10:34-48; doi:10.2174/1874613601610010034

[19] Bordes J, Cungi P, Savoie P, Bonnet S, Kaiser E. Usefulness of routine preoperative testing in a developing country: a prospective study. Pan African Medical Journal. 2015;21(1).

[20] Joseph BN, Jamil AM, Aya BM, Yahya AI, Dangiwa DA, Jangkam DN, Dapar ML. Mandatory HIV testing as a prerequisite for surgical procedures: Perspectives on rights and ethics. South African Journal of Bioethics and Law. 2018;11(2):70-4.

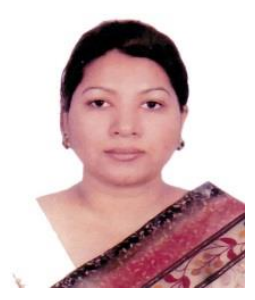

Dr. Nahida Sultana born in Dhaka, Bangladesh in 1977. She got her M.B.B.S from Dhaka University in the year 2004 and MD. (Virology) in 2017 from BSMMU.

Nahida Sultana, MD. (Bangladesh), is a Virologist. On her 8 years of teaching career, she has a teaching experience in GeneralVirology, clinical Virology, Microbiology , Immunology

(8) peer reviewed articles. Epidemiology , Biostatics, Genomics. Nahida has

She is a life member of Bangladesh Society of Medical Virology , member of American Virology Association, Asian Pacific Association for the study of the liver, Bangladesh Society of Medical Microbiology Medscope org, Forum for the Study of liver Bangladesh, Heamatology Society of Bangladesh, Society of Clinical care Medicine and clinical Pathology Society of Bangladesh.

She Secure $1^{\text {st }}$ positision for poster presentation in The $6^{\text {th }}$ National Convention 2011, Bangladesh Society Of Medical Microbiology. December 9-10, 2011, Dhaka, Bangladesh. 


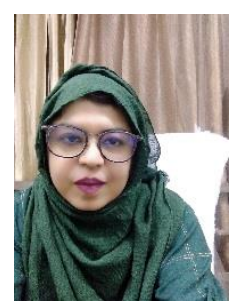

Dr. Mahbuba Sharmin born in Dhaka, Bangladesh in 1983. She got her M.B.B.S from Dhaka University in the year 2006 and FCPS (Haematology) in 2019 from BSMMU.

Mahbuba Sharmin, FCPS (Bangladesh), is a Heamatologist. On her 10 years of career, she has a working experience in clinical Haematology, Stem cell Transplant, Immunology , Epidemiology , Biostatics , Genomics. Mahbuba has (13) peer reviewed articles.

She is a life member of Heamatology Society of Bangladesh, Bangladesh Society of Medical Virology, member of American Virology Association, Asian Pacific Association for the study of the liver, Bangladesh Society of Medical Microbiology Medscope org, Forum for the Study of liver Bangladesh , Society of Clinical care Medicine and clinical Pathology Society of Bangladesh.

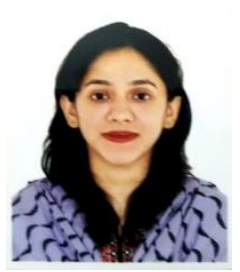

Dr. Tangia Muquith born in Dhaka, Bangladesh in 1986. She got her M.B.B.S from Dhaka University in the year 2013 and FCPS (Heamatology) in 2016 from BSMMU.

Tangia Muquith, FCPS (Bangladesh), is a Heamatologist. On her 6 years of working career, she has a working experience in clinical Haematology, Stem cell Transplant, Immunology , Epidemiology, Biostatics, Genomics. Tangia has (9) peer reviewed

articles.

She is a life member of Bangladesh Society of Medical Haematology, member of American Haematology Association, European Haematology Association, Microbiology Medscope org, Forum for the Study of liver Bangladesh , Heamatology Society of Bangladesh, Society of Clinical care Medicine and clinical Pathology Society of Bangladesh.

She got award for poster presentation in APBMT(Asia Pacific Bone

Marrow Transplant) Annual Meeting, Singapore, 2016 and $\operatorname{NCAM(6~}$ NCIS Annual Research Meeting,Singapore, July 2019.

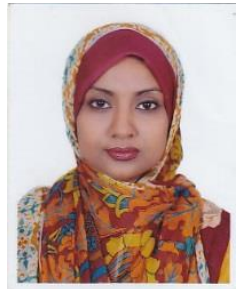

Dr. Umme Shahera born in Dhaka, Bangladesh in 1979. She got her M.B.B.S from Chittagong University in the year 2005 and M.phil (Virology) in 2014 from BSMMU.

Umme Shahera, M.phil (Bangladesh), is a Virologist. On her 6 years of teaching career, she has a teaching experience in General Virology, clinical Virology, Microbiology, Immunology, Epidemiology, Biostatics, Genomics. Umme has

(13) peer reviewed articles.

She is a life member of Bangladesh Society of Medical Virology , member of American Virology Association, Asian Pacific Association for the study of the liver, Bangladesh Society of Medical Microbiology Medscope org, Forum for the Study of liver Bangladesh, Heamatology Society of Bangladesh , Society of Clinical care Medicine and clinical Pathology Society of Bangladesh. 